design and supervision of project. $\mathrm{JH}$ participated in development of study design, methods, and questionnaire for European study, management and screening of European population, and data coding. SP participated in screening South Asians, community liaison and recruitment to study, and data coding. NA contributed to development of South Asian questionnaire, translation, sampling, screening, recruitment, and data preparation. NU, MW, JY, LW, KGMMA, JH, SP, and NA commented on the manuscript. CT participated in screening, development of questionnaire, recruitment, and community liaison. BW managed and participated in screening for European and South Asian samples and helped with entry and preparation of data for analysis. DK participated in coordination of recruitment and data collection for the South Asian study, data analysis on response rates, and drafting text. AK participated in screening, development of questionnaire, community liaison, and recruitment. ML advised on biochemical methods, supervised laboratories doing biochemical tests, and had responsibility for $\mathrm{Lp}(\mathrm{a})$ lipoprotein assays. AT participated in the $\mathrm{Lp}(\mathrm{a})$ lipoprotein study and provided data and advice on $\mathrm{Lp}$ (a) lipoprotein. $\mathrm{RB}, \mathrm{GA}, \mathrm{NU}$, and $\mathrm{MW}$ are the study guarantors.

Funding: Barclay Trust, British Diabetic Association, Newcastle Health Authority, research and development directorate of the Northern Regional Health Authority, Department of Health, and British Heart Foundation.

Competing interests: None declared.

1 Balarajan R. Ethnicity and variations in mortality from coronary heart disease. Health Trends 1996;28:45-51.

2 McKeigue P, Sevak L. Coronary heart disease in South Asian communities. London: Health Education Authority, 1994.

3 McKeigue PM. Coronary heart disease in South Asians overseas: a review. J Clin Epidemiol 1989;42:597-609.

4 Bhopal RS. Several key facts need to be considered. BMJ 1996;312:375.

5 Shaukat N, de Bono DP. Are Indo-origin people especially susceptible to coronary artery disease. Postgrad Med J 1994;70:315-8.

6 Williams R, Bhopal R, Hunt K. Coronary risk in a British Punjabi population: comparative profile of non-biochemical factors. Int J Epidemiol 1994:23:28-37.

7 Nazroo J. The health of Britain's ethnic minorities. London: Policy Studies Institute, 1997.
8 Harland JO, Unwin N, Bhopal RS, White M, Watson B, Laker M, et al. Low levels of cardiovascular risk factors and coronary heart disease in a UK Chinese population. J Epidemiol Community Health 1997;51:636-42.

9 Unwin N, Harland J, White M, Bhopal RS, Winocour P, Stephenson P, et al. Body mass index, waist circumference, waist-hip ratio, and glucose intolerance in Chinese and Europid adults in Newcastle, UK. J Epidemiol Community Health 1997;51:160-6.

10 Coldman A, Braun T, Gallagher R. The classification of ethnic status using name information J Epidemiol Community Health 1988;42:390-5.

11 WHO MONICA Project. Geographical variation in the major risk factors of coronary heart disease in men and women aged 35-64 years. World Health $\operatorname{Org} Q 1988 ; 41: 115-38$.

12 Flegal KM, Carroll MD, Kuuczmarski RJ, Johnson CL. Overweight and obesity in the United States: prevalence and trends, 1960-1994. Int J Obesity Relat Metab Disord 1998:22:39-47

13 Bedfont Scientific. Operator's manual for mini and micro smokerlyzers. Upchurch: Bedfont Scientific, 1993

14 Rose G, Blackburn A, Gillum R, Prineas R. Cardiovascular survey methods. 2nd ed. Geneva: World Health Organisation, 1982.

15 Coombs M, Raybould S, Long CA. Index of deprivation. London: Department of Environment, 1992.

16 Modood T, Berthoud R, eds. Ethnic minorities in Britain. London, Policy Studies Institute, 1997.

17 McKeigue PM, Shah B, Marmot MG. Relation of central obesity and insulin resistance with high diabetes prevalence and cardiovascular risk in South Asians. Lancet 1991;337:382-6.

18 McKeigue PM, Marmot MG, Adelstein AM. Diet and risk factors for coronary heart disease in Asians in Northwest London. Lancet 1985;ii:108690.

19 McKeigue PM. Mortality from coronary heart disease in Asian communities in London. BMJ 1988;297:903-7.

20 Marmot MG, Adelstein AM, Bulusu L. Immigrant mortality in England and Wales 1970-1978. Causes of death by country. Studies on medical and population subjects. London: HMSO, 1984.

21 Nath BS, Murthy R. Cholesterol in Indian ghee. Lancet 1988;ii:39.

22 Pais P, Pogue J, Gerstein H, Zachariah E, Savitha D, Jayprakash S, et al. Risk factors for acute myocardial infarction in Indians: a case-control study Lancet 1996:348:358-63.

23 Fowler PBS. Diet and risk factors for coronary heart disease in Asians in north west London. Lancet 1985;ii:1363.

24 Barker DJP. Mothers, babies and disease in later life. London: BMJ Publishing, 1994.

25 Gupta S, de Belder A, Hughes LO. Avoiding premature coronary deaths in Asians in Britain. BMJ 1995;311:1035-6.

26 Mendall M. Inflammatory responses and coronary heart disease. BMJ 1998;316:953-4.

(Accepted 28 April 1999)

\title{
Influence of bacterial vaginosis on conception and miscarriage in the first trimester: cohort study
}

\author{
S G Ralph, A J Rutherford,J D Wilson
}

Department of

Genitourinary

Medicine, General

Infirmary at Leeds,

Leeds LS1 3EX

S G Ralph,

specialist registrar

J D Wilson,

consultant physician

Reproductive

Medicine Unit,

General Infirmary

at Leeds

A J Rutherford,

clinical director

Correspondence to:

J D Wilson

jdwilson@dunham.

freeuk.com

BMJ 1999;319:220-3

\begin{abstract}
Objectives To assess whether bacterial vaginosis affects the rates of conception and miscarriage in the first trimester.

Design Cohort study.

Setting Assisted conception unit of a teaching hospital in Leeds.

Participants 867 consecutive women undergoing in vitro fertilisation.

Interventions Screening for bacterial vaginosis with a Gram stained vaginal smear before egg collection.

Main outcome measures The presence of bacterial vaginosis or normal vaginal flora, and the rate of conception and miscarriage in the first trimester. Results 190 of 771 (24.6\%) women had bacterial vaginosis. No difference in conception rate was found between those women with bacterial vaginosis and those with normal vaginal flora: 61 women (32.1\%) and 146 of 493 women (29.6\%) respectively (relative risk $1.08,95 \%$ confidence interval 0.85 to 1.39 ; odds
\end{abstract}

ratio $1.12,0.77$ to 1.64$)$. However, 22 women (31.6\%) with bacterial vaginosis who conceived had a significantly increased risk of miscarriage in the first trimester compared with 27 women (18.5\%) with normal vaginal flora (crude relative risk $1.95,1.11$ to 3.42 ; crude odds ratio $2.49,1.21$ to 5.12 ). This increased risk remained significant after adjustment for factors known to increase the rate of miscarriage: increasing maternal age, smoking, history of three or more miscarriages, no previous live birth, and polycystic ovaries (adjusted relative risk 2.03, 1.09 to 3.78; adjusted odds ratio 2.67, 1.26 to 5.63).

Conclusions Bacterial vaginosis does not affect conception but is associated with an increased risk of miscarriage in the first trimester in women undergoing in vitro fertilisation, independent of other risk factors.

\section{Introduction}

Bacterial vaginosis is the most common cause of abnormal vaginal discharge among women of 
childbearing age. Prevalence rates of $13 \%$ to $31 \%$ have been reported in pregnant women. ${ }^{1-5}$

Bacterial vaginosis develops when normal vaginal lactobacilli are replaced by an overgrowth of Gardnerella vaginalis, anaerobes, and mycoplasmas. Factors responsible for this change are not fully understood. Bacterial vaginosis in pregnancy predisposes to an increased risk of late miscarriage, ${ }^{34}$ preterm labour, ${ }^{1-5}$ postpartum endometritis, ${ }^{6}$ and low birthweight infants. ${ }^{5}$ The reported odds ratios for preterm births were between 1.4 and $6.9,^{1-5}$ the highest rates being when bacterial vaginosis was identified before 16 weeks of gestation. ${ }^{134}$ Riduan et al screened for bacterial vaginosis in pregnant women in both the mid and third trimester. ${ }^{2}$ The authors found a significant risk of preterm birth when bacterial vaginosis was diagnosed between 16 and 20 weeks of gestation, but not if bacterial vaginosis developed just in the third trimester. The highest relative risk of preterm birth was reported at 6.9 by Kurki et al. All the women were screened between 8 and 17 weeks of gestation, which is earlier than in other studies. Hay et $\mathrm{al}^{3}$ and McGregor et $\mathrm{al}^{4}$ found an increased relative risk of 3.9 and 3.1 for miscarriage in the mid trimester, when bacterial vaginosis was diagnosed before 16 weeks of gestation. The findings of these studies support a pathological role for bacterial vaginosis in the mid rather than third trimester, as was previously thought. Consequently, bacterial vaginosis may have a detrimental effect on the outcome of the first trimester, yet there are no published data on bacterial vaginosis in early pregnancy.

We aimed to assess whether bacterial vaginosis affects the rate of conception and miscarriage in the first trimester. We chose to study a cohort of women undergoing in vitro fertilisation, for two reasons: the exact date of conception was known, and vaginal samples could be taken at this time.

\section{Participants and methods}

\section{Participants}

We recruited 867 consecutive women undergoing in vitro fertilisation between April 1996 and June 1997 at the assisted conception unit of a teaching hospital in Leeds. All participants gave their written consent to participate, and ethical approval for our study was obtained from the local ethics committee. The women entered the study on the day of egg collection. We recorded baseline data for age, smoking habit, ethnic origin, previous obstetric history, and reason for infertility.

\section{Methods}

Vaginal samples

The women were treated with a conventional superovulation regimen of pituitary downregulation followed by stimulation with gonadotropins. ${ }^{7}$ Immediately before egg collection, a non-lubricated bivalve speculum was inserted into the vagina, and a sample was taken from the vaginal walls and posterior fornix with a sterile cotton swab. The swab was smeared on to a glass slide then air dried and Gram stained. The women were simultaneously screened for sexually transmitted infections that can predispose to miscarriage. A vaginal sample was cultured for Trichomonas vaginalis (in-house culture medium), and endocervical samples were tested for Neisseria gonorrhoeae (GC Agar
Base, Unipath, Basingstoke) and Chlamydia trachomatis (enzyme immunoassay; Micro Trak, Behring Diagnostics, Milton Keynes).

The slides were read by two observers (SGR and JDW), blinded to each other's results and to pregnancy outcome. Modified Spiegel's criteria were used to diagnose bacterial vaginosis on Gram stain, as described by Hay et al. ${ }^{3}$ Thus, we graded flora as normal (predominantly lactobacilli), intermediate (reduced lactobacilli mixed with other morphotypes), and bacterial vaginosis (few or absent lactobacilli with greatly increased numbers of $G$ vaginalis, other morphotypes, or both). When the observers disagreed, the slide was reviewed until consensus was reached.

\section{Egg collection}

The vagina was cleansed with normal saline, and eggs were collected transvaginally under ultrasound guidance. Forty eight hours after egg collection, the vagina was washed with normal saline, and up to three embryos were placed into the uterus transcervically using a Wallace catheter (SIMS Portex, Hythe). The luteal phase was supported with $400 \mathrm{mg}$ progesterone daily through vaginal pessaries.

\section{Pregnancy confirmation}

Pregnancy was confirmed 14 days after egg collection by measuring serum concentrations of $\beta$ human chorionic gonadotropin (Delfia, EG and G Wallac, Milton Keynes). This pregnancy test has a detection limit of $2 \mathrm{U} / \mathrm{l}$ of $\beta$ human chorionic gonadotropin: we considered concentrations greater than $10 \mathrm{U} / 1$ as a positive result. When the concentration was less than $10 \mathrm{U} / 1$ we repeated the test 2 days later, and if the concentration had doubled, we considered this a positive result. These concentrations give a specificity of $100 \%$ for pregnancy. ${ }^{8}$ Follow up ultrasound at 6 and 8 weeks of gestation confirmed clinical pregnancy. We followed all the women through to completion of the pregnancy.

\section{Pregnancy loss}

We subdivided pregnancy loss before 13 weeks of gestation into (a) preclinical pregnancy (a positive pregnancy test followed by spontaneous abortion before 6 weeks of gestation, before confirmation of the pregnancy by ultrasonography), (b) anembryonic pregnancy (confirmation of a gestational sac by ultrasonography at 6 weeks of gestation but no fetus identified), (c) missed abortion (confirmation of a gestational sac and fetus by ultrasonography but no fetal heart visible), and $(d)$ spontaneous abortion (confirmation of a viable fetus by ultrasonography, which aborts before 13 weeks of gestation).

\section{Statistical methods}

We used relative risk and odds ratio to compare the rates of conception and miscarriage in the first trimester among women with bacterial vaginosis and those with normal vaginal flora, and to assess the univariate risk of miscarriage due to other known factors. We investigated any association between bacterial vaginosis and these factors with Wilcoxon 2 sample, $\chi^{2}$, or Fisher's exact tests. We included all the factors in a model to estimate by relative risk the probability of early miscarriage, and we used logistic regression to assess the significance of the factors by odds ratio, having adjusted for the other variables. 
Table 1 Previous obstetric history of 771 women undergoing in vitro fertilisation

\begin{tabular}{lc} 
Obstetric history & No (\%) of patients \\
\hline Never pregnant & $439(57.0)$ \\
\hline At least one live birth & $128(16.6)$ \\
\hline Miscarriage only & $118^{\star}(15.3)$ \\
\hline Termination only & $45(5.8)$ \\
\hline Ectopic pregnancy only & $41(5.3)$ \\
\hline
\end{tabular}

*Includes 16 women with history of $\geqslant 3$ miscarriages.

Table 2 Types of miscarriage occurring in first trimester in two groups of women undergoing in vitro fertilisation

\begin{tabular}{lcc} 
Miscarriage & $\begin{array}{c}\text { Bacterial } \\
\text { vaginosis }(\mathbf{n}=\mathbf{2 2})\end{array}$ & $\begin{array}{c}\text { Normal vaginal flora } \\
(\mathbf{n}=\mathbf{2 7})\end{array}$ \\
\hline Preclinical & 18 & 16 \\
\hline Anembryonic & 0 & 4 \\
\hline Missed abortion & 2 & 4 \\
\hline Spontaneous abortion & 2 & 3 \\
\hline
\end{tabular}

\section{Results}

Between April 1996 and June 1997 we recruited 867 consecutive women undergoing in vitro fertilisation. We excluded 96 women (11.1\%): 75 (8.7\%) failed to reach the embryo transfer stage, and in 20 cases $(2.3 \%)$ slides were incorrectly labelled or broken. One woman had an ectopic pregnancy, which was surgically removed. No significant differences were found between the baseline data of those excluded and the study cohort.

Overall, 732 of the women $(94.9 \%)$ were white, the median age was 33 years, and $139(18 \%)$ were smokers. Table 1 outlines the previous obstetric history of the study cohort. As no sexually transmitted infections were detected in the first 200 women we recruited, we stopped screening.

The vaginal slides were graded as normal in 493 women $(63.9 \%)$, intermediate in $88(11.4 \%)$, and bacterial vaginosis in $190(24.6 \%)$. Fifty five slides $(7.1 \%)$ required review before a consensus was reached. Overall, 237 of the women (30.7\%) conceived: 146 women $(29.6 \%)$ with normal vaginal flora, $30(34 \%)$ with intermediate vaginal flora, and $61(32.1 \%)$ with bacterial vaginosis. No difference in conception rate was found between the women with bacterial vaginosis and those with normal vaginal flora (relative risk $1.08,0.85$ to 1.39 ; odds ratio $1.12,0.77$ to 1.64 ).

Table 3 Risk factors for miscarriage in 771 women undergoing in vitro fertilisation

\begin{tabular}{lcc} 
Risk factor & Odds ratio $(95 \%$ Cl) & Relative risk $\mathbf{( 9 5 \%} \mathbf{C l})$ \\
\hline Increasing age & $1.03^{\star}(0.95$ to 1.12$)$ & $1.01^{*}(0.94$ to 1.08$)$ \\
\hline Smoking & $1.05(0.47$ to 2.33$)$ & $1.04(0.52$ to 2.08$)$ \\
\hline Polycystic ovary syndrome & $1.68(0.55$ to 5.18$)$ & $1.46(0.58$ to 3.67$)$ \\
\hline$\geqslant 3$ miscarriages & $1.63(0.14$ to 18.31$)$ & $1.42(0.20$ to 10.26$)$ \\
\hline No previous live birth & $1.54(0.70$ to 3.41$)$ & $1.38(0.70$ to 2.69$)$ \\
\hline${ }^{*}$ For each additional year. &
\end{tabular}

Table 4 Adjusted relative risks and odds ratios in 771 women undergoing in vitro fertilisation

\begin{tabular}{lll} 
Risk factor & Relative risk $\mathbf{( 9 5 \%} \mathbf{~ C l )}$ & Odds ratio $\mathbf{( 9 5 \%} \mathbf{~ C l})$ \\
\hline Bacterial vaginosis & $2.03(1.09$ to 3.78$)$ & $2.67(1.26$ to 5.63$)$ \\
\hline Increasing age & $1.02(0.94$ to 1.10$)$ & $1.03(0.94$ to 1.12$)$ \\
\hline Smoking & $0.83(0.38$ to 1.78$)$ & $0.75(0.30$ to 1.87$)$ \\
\hline Polycystic ovary syndrome & $1.29(0.47$ to 3.52$)$ & $1.46(0.43$ to 5.03$)$ \\
\hline$\geqslant 3$ miscarriages & $1.26(0.14$ to 11.13$)$ & $1.45(0.09$ to 22.20$)$ \\
\hline Previous live birth & $1.11(0.53$ to 2.31$)$ & $1.17(0.49$ to 2.79$)$ \\
\hline
\end{tabular}

Of the 237 women who conceived, $56(23.6 \%)$ miscarried during the first 13 weeks of gestation: 27 of 146 women $(18.5 \%)$ with normal vaginal flora, 7 of 30 women $(23.3 \%)$ with intermediate vaginal flora, and 22 of 61 women $(36.1 \%)$ with bacterial vaginosis. A significantly increased risk of miscarriage was found in women with bacterial vaginosis compared with women with normal vaginal flora $(1.95,1.11$ to $3.42 ; 2.49,1.21$ to 5.12 ).

Table 2 classifies the miscarriages that occurred in the first trimester. No difference was found between the two groups in distribution of timing of the miscarriages: preclinical miscarriages occurred in 18 of 22 women with bacterial vaginosis and 16 of 27 women with normal flora $\left(\mathrm{P}=0.09, \chi^{2}\right)$. A significant difference was found, however, in the proportions of conceptions resulting in preclinical pregnancies: 18 of 61 pregnancies $(29.5 \%)$ in women with bacterial vaginosis compared with 16 of 146 pregnancies $(11.0 \%)$ in those with normal vaginal flora $(2.69,1.47$ to $4.92 ; 3.4,1.5$ to 7.8). This risk is greater than that of overall miscarriage in the first trimester in women with bacterial vaginosis.

Increasing maternal age, smoking, polycystic ovary syndrome, history of three or more miscarriages, and no previous live birth all increase the risk of miscarriage in the first trimester. We performed a statistical analysis to assess whether there was any association between these factors and miscarriage. We found no significant associations, although our study was not powered to assess these as risk factors (table 3).

To eliminate an uneven distribution of these factors between the two groups of women, we sought any associations between the factors and bacterial vaginosis. The proportions of women with polycystic ovary syndrome $(\mathrm{P}=0.147$, Fisher's exact $)$ and three or more previous miscarriages $(\mathrm{P}=1.000$, Fisher's exact) did not differ between the two groups, but the numbers were small in each category. Distributions of age, smoking habit, and previous live birth, however, were significantly different. Women with bacterial vaginosis were more likely to smoke $\left(\mathrm{P}=0.001, \chi^{2}\right)$ and less likely to have previously given birth $\left(\mathrm{P}=0.003, \chi^{2}\right)$. Women with normal vaginal flora were significantly older than women with bacterial vaginosis $(\mathrm{P}=0.008$, Wilcoxon 2 sample).

After adjustment for these variables, we found no other factor to be significant (table 4). The increased risk of miscarriage with bacterial vaginosis remained (adjusted relative risk 2.03, 1.09 to 3.78; adjusted odds ratio $2.67,1.26$ to 5.63 ).

\section{Discussion}

Our study is the first to describe a definite association between bacterial vaginosis and miscarriage in the first trimester, and it suggests that the pathological processes of bacterial vaginosis may begin early in pregnancy. Previously published studies could not have reached this conclusion as these screened for bacterial vaginosis at 7-8 weeks of gestation at the earliest. In our study most of the miscarriages in the first trimester had already occurred by then.

We believe these results are genuine for several reasons. Firstly, the in vitro fertilisation procedures were identical in both groups of women. Secondly, we eliminated other infective causes of miscarriage. Thirdly, the association between bacterial vaginosis 
and miscarriage in the first trimester persisted after adjusting for other variables known to increase the risk of miscarriage-namely, smoking, older age, three or more previous miscarriages, polycystic ovary syndrome, and no previous live birth. Fourthly, an increasing miscarriage rate was seen with increasing abnormality of the vaginal flora: $18.5 \%$ in women with normal vaginal flora, $23.3 \%$ in women with intermediate vaginal flora, and $36.1 \%$ in women with bacterial vaginosis, as would be expected with a cause and effect relation. We did not include the intermediate group in the analysis because Hillier et $\mathrm{al}^{9}$ showed that intermediate vaginal flora can be a transitional phase between normal vaginal flora and bacterial vaginosis in pregnant women, with $32 \%$ of women developing bacterial vaginosis and $30 \%$ reverting to normal vaginal flora within 13 weeks. Fifthly, the overall miscarriage rate of $23.6 \%$ is in keeping with other studies of early pregnancy loss. Wilcox et al ${ }^{10}$ performed daily urinary assays for $\beta$ human chorionic gonadotropin in couples trying to conceive. The total pregnancy loss was $31 \%$ : preclinical loss in $22 \%$ of women and clinically recognised miscarriages in $9 \%$. Within our miscarriage rate of $23.6 \%$, however, the proportion of women with bacterial vaginosis who miscarried was significantly higher than that of the women with normal vaginal flora, the increased risk being equivalent to one extra miscarriage for every six pregnant women with bacterial vaginosis.

The pathogenesis of miscarriages associated with bacterial vaginosis is not known. Most of the miscarriages in our study were preclinical, which represents a failure of implantation or early embryonic development. The increased risk of preclinical pregnancy was higher than the overall risk of a miscarriage in the first trimester (crude relative risk 2.69 and 1.95 respectively). Korn et $\mathrm{al}^{11}$ found plasma cell endometritis in $45.5 \%$ of women who had bacterial vaginosis but no other vaginal or cervical infections and no symptoms or signs of upper genital tract infection. If endometritis was present with bacterial vaginosis before in vitro fertilisation, this could impair implantation or early embryonic development.

An unavoidable component of in vitro fertilisation involves breaching the cervix with a catheter at the time of embryo transfer, thereby potentially assisting vertical spread of vaginal bacteria to the upper genital tract. Pelvic inflammatory disease after egg collection is, however, rare with a reported incidence of $0.2 \%$ to $0.5 \%$ per cycle ${ }^{12-14}$ and is mainly associated with accidental puncture of bowel or hydrosalpinx. Pelvic infection after embryo transfer is even rarer, with one reported case only. ${ }^{15}$ This therefore seems an unlikely cause of the miscarriages.

We specifically chose women undergoing in vitro fertilisation for two reasons: the exact time of conception was known, and a vaginal sample could be taken at this time. Such accurate information would be difficult to obtain in the naturally conceiving population. Whether these results apply to those conceiving naturally depends on the underlying cause of the miscarriages. If miscarriages were due to pre-existing endometritis these results would apply to all women trying to conceive either naturally or by assisted conception techniques. If instrumentation was responsible, an increase in miscarriage rate in the first trimester would be unlikely among the naturally conceiving population.

\section{Key messages}

- Bacterial vaginosis does not affect conception rate

- Bacterial vaginosis is associated with a two-fold risk of miscarriage in the first trimester

- The increased miscarriage rate is equivalent to one extra miscarriage for every six pregnant women with bacterial vaginosis

- The most likely cause of the miscarriages is due to pre-existing endometritis affecting implantation or early embryonic development, which could also affect naturally conceived pregnancies

Finally, infertility and in vitro fertilisation place a financial burden on the health service and a great personal cost on those affected. An intervention study is therefore required to assess whether treatment of bacterial vaginosis reduces the rate of associated miscarriage. As the diagnosis and treatment of bacterial vaginosis are simple and cheap, only a small improvement in pregnancy outcome would be required to be economically beneficial.

We thank Dr S Bogle of Aysgarth Statistical Consultancy for her help with statistical analysis.

Contributors: JDW conceived and designed the study. SGR coordinated the study and collected the baseline and outcome data. AJ Rutherford recruited and clinically cared for the participants. JDW and SGR interpreted the vaginal slides and analysed the data. SGR, AJR, and JDW wrote the paper. JDW will act as guarantor for the paper.

Funding: None.

Competing interests: None declared.

1 Kurki T, Sivonen A, Renkonen O, Savia E, Ylikorkala O. Bacterial vaginosis in early pregnancy and pregnancy outcome. Obstet Gynaecol 1992;80:173-7.

2 Riduan JM, Hillier SL, Utomo B, Wiknjosastro G, Linnan M, Kandun N. Bacterial vaginosis and prematurity in Indonesia: association in early and late pregnancy. Am J Obstet Gynecol 1993;169:175-8.

3 Hay PE, Lamont RF, Taylor-Robinson D, Morgan DJ, Ison C, Pearson J Abnormal bacterial colonisation of the genital tract and subsequent preterm delivery and late miscarriage. BMJ 1994;308:295-8.

4 McGregor JA, French JI, Parker R, Draper D, Patterson E, Jones W, et al. Prevention of premature birth by screening and treatment for common genital tract infections: results of a prospective controlled evaluation. Am Jenital tract infections: results of a precol 1995;173:157-67.

5 Hillier SL, Nugent RP, Eschenbach DA, Krohn MA, Gibbs RS, Martin DH, et al. Association between bacterial vaginosis and preterm delivery of a low-birth-weight infant. N Engl J Med 1995;333:1737-42.

6 Watts DH, Krohn MA, Hillier SL, Eschenbach DA. Bacterial vaginosis as a risk factor for post-cesarean endometritis. Obstet Gynaecol 1990;75:52-8.

7 Rutherford AJ, Subak-Sharpe RJ, Dawson KJ, Margara RA, Franks S, Winston RML. Improvement of in vitro fertilisation after treatment with Winston RML. Improvement of in vitro fertilisation after treatment with
buserelin, an agonist of luteinising hormone releasing hormone. BMJ 1988;296:1765-8

8 Stenman U-H, Alfthan H, Ranta T, Vartiainen E, Jalkanen J, Seppala M. Serum levels of human chorionic gonadotropin in nonpregnant women and men are modulated by gonadotropin-releasing hormone and sex steroids. J Clin Endocrinol Metab 1987;64:730-6.

9 Hillier SL, Krohn MA, Nugent RP, Gibbs RS for the Vaginal Infections and Prematurity Study Group. Characteristics of three vaginal flora patterns assessed by Gram stain among pregnant women. Am J Obstet Gynecol 1992;166:938-44.

10 Wilcox AJ, Weinberg CR, O'Connor JF, Baird DB, Schlatterer JP, Canfield $\mathrm{RE}$, et al. Incidence of early loss of pregnancy. $N$ Engl $J$ Med 1988;319:189-94.

11 Korn AP, Bolan G, Padian N, Ohm-Smith M, Schachter J, Landers DV. Plasma cell endometritis in women with symptomatic bacterial vaginosis. Obstet Gynaecol 1995;85:387-90.

12 Howe RS, Wheeler C, Mastroianni L Jr, Blasco L, Tureck R. Pelvic infection after transvaginal ultrasound-guided ovum retrieval. Fertil Steril 1988;49:726-8.

13 Curtis P, Amso N, Keith E, Bernard A, Shaw RW. Evaluation of the risk of pelvic infection following transvaginal oocyte recovery. Hum Reprod 1992;7:625-6.

14 Ashkenazi J, Farhi J, Dicker D, Feldberg D, Shalev J, Ben-Rafael Z. Acute pelvic inflammatory disease after oocyte retrieval: adverse effects on the result of implantation. Fertil Steril 1994:61:526-8.

15 Sauer MV, Paulson RJ. Pelvic abscess complicating transcervical embryo transfer. Am J Obstet Gynecol 1992;166:148-9.

(Accepted 12 May 1999) 